\title{
Uso de diferentes fontes de carbono por estirpes de Gluconacetobacter diazotrophicus isoladas de cana-de-açúcar
}

\author{
Edilene Alves Barbosa(1), Liamara Perin ${ }^{(2)}$ e Veronica Massena Reis ${ }^{(2)}$
}

\begin{abstract}
(1)Escola Agrotécnica Federal de Salinas, Rodovia Salinas-Taiobeiras, BR 251, Km 2, Fazenda Varginha, CEP 39560-000 Salinas, MG. E-mail: eabsal@terra.com.br (2)Embrapa Agrobiologia, Km 7, BR 465, Caixa Postal 74.505, CEP 23890-000 Seropédica, RJ. E-mail: liaperin@yahoo.com.br, veronica@cnpab.embrapa.br
\end{abstract}

\begin{abstract}
Resumo - O objetivo deste trabalho foi quantificar a população de Gluconactobacter diazotrophicus presente em plântulas de 34 variedades de cana-de-açúcar, e caracterizar os isolados quanto à capacidade de utilizar diversas fontes de carbono e formar pigmento róseo em presença de luz. A população de G. diazotrophicus foi quantificada pela técnica do número mais provável e isolada em meios de cultura semi-seletivos. A população de G. diazotrophicus foi maior no sistema radicular do que na parte aérea, e maior nas variedades brasileiras de cana-de-açúcar. Os isolados utilizaram poucas fontes de carbono, e aqueles obtidos do sistema radicular utilizaram maior número de fontes, em comparação aos da parte aérea. Apenas a estirpe padrão Ppe-4 e quatro outros isolados formam pigmento róseo em presença de luz. A baixa variação observada pode estar relacionada com o habitat ou com a adaptação dessa população às condições específicas do interior das plantas e, por isso, a estrutura genética da população dessas bactérias é limitada e conservada.
\end{abstract}

Termos para indexação: diversidade, bactérias diazotróficas, endófitos.

\section{Use of different carbon sources by strains of Gluconacetobacter diazotrophicus isolated from sugarcane}

\begin{abstract}
The objective of this work was to quantify the population of Gluconacetobacter diazotrophicus present in plantlets of 34 sugarcane varieties and to characterize the isolates according to their capacity to use carbon sources and produce pink pigments under light. G. diazotrophicus population was estimated using the most probable number technique, and then, isolated in semi-selective culture media. The highest population number of G. diazotrophicus was found in the roots; Brazilian varieties presented the highest population. The isolates used little carbon sources, and those strains obtained from the root used the highest number of carbon sources. Only the strain Ppe-4 and four other ones produce pink pigments under light. The low variation observed may be related to the habitat or to the adaptation of this population to specific internal plant conditions, and for this reason, the genetic structure of these bacteria is limited and preserved.
\end{abstract}

Index terms: diversity, diazotrophic bacteria, endophytes.

\section{Introdução}

A cana-de-açúcar acumula de 180 a 250 kg de N para produzir $100 \mathrm{Mg} \mathrm{ha}^{-1}$ de colmos em cana planta (Orlando Filho et al., 1980), sendo que quase toda a planta é retirada no processo de colheita. A cana é beneficiada pela associação com bactérias diazotróficas, que fixam o nitrogênio do ar, e entre as gramíneas, é a cultura que recebe maior contribuição deste processo.

Inúmeros diazotróficos associativos foram isolados de cana-de-açúcar. Entre eles, Gluconacetobacter diazotrophicus (Cavalcante \& Döbereiner, 1988), um importante organismo, pois ocorre em números elevados em raízes e colmos, tolera meio com altas concentrações de açúcar e acidez, e pode crescer em pH 3. Além disto, é capaz de fixar nitrogênio em presença de $\mathrm{O}_{2}$ até à concentração de $4 \mathrm{kPa}$, bem maior que a tolerância verificada para o gênero Azospirillum (Reis \& Döbereiner, 1998).

Estudos com balanço de $\mathrm{N}$ e quantificação do $\mathrm{N}$ assimilado, por uso de fertilizante marcado $\operatorname{com}{ }^{15} \mathrm{~N}$, mostraram que variedades brasileiras de cana-de-açúcar podem obter até $70 \%$ do $\mathrm{N}$ necessário para seu 
desenvolvimento, por meio da fixação biológica de nitrogênio (FBN) (Lima et al., 1987; Urquiaga et al., 1992).

Muthukumarasamy et al. (1999) também verificaram benefícios da inoculação de G. diazotrophicus na cultura da cana-de-açúcar, na Índia. Este benefício pode ser devido à FBN, ou à produção de fitormônios pelas bactérias (Fuentes-Ramirez et al., 1993; Bastian et al., 1999).

Segundo Canuto et al. (2003), a inoculação de bactérias diazotróficas, em plantas de cana-de-açúcar micropropagadas, mostrou-se variável e dependente de vários fatores, inclusive o genótipo vegetal e o ambiente.

Como não há correlação entre o número populacional e a quantidade de nitrogênio fixado biologicamente (Reis Junior et al., 2000), estudos de ecologia de G. diazotrophicus poderão contribuir para uma melhor exploração desse processo na cultura da cana-de-açúcar.

Em contribuição ao conhecimento do comportamento de Gluconacetobacter diazotrophicus, o objetivo deste estudo foi quantificar sua população em 34 variedades de cana-de-açúcar e caracterizar os isolados quanto à capacidade de utilizar fontes de carbono e formar pigmentação rósea, em presença da luz.

\section{Material e Métodos}

As cultivares de cana-de-açúcar analisadas foram mantidas no Campo Experimental da Pesagro, Empresa de Pesquisa Agropecuária do Estado do Rio de Janeiro, no Município de Campos dos Goytacazes, Região Norte do Estado do Rio de Janeiro, a 21044'47"S, 41ํำ'24"O e altitude de $12 \mathrm{~m}$ do nível do mar. O clima é Aw, segundo a classificação de Köppen, tropical quente e úmido, com período seco no inverno e chuvoso no verão, com precipitação média anual de $1.020 \mathrm{~mm}$. As cultivares foram plantadas em Neossolo (Embrapa, 1999), sem tratos culturais por longo tempo, encontrando-se em pousio.

Em março de 1996, foram coletados colmos de 34 cultivares de cana-de-açúcar, de diferentes origens geográficas. Os colmos foram enviados para a Embrapa Agrobiologia, Seropédica, RJ, onde foram subdivididos em toletes, com três gemas viáveis, em média. O material vegetal foi acomodado em bandejas de plástico, preenchidas com areia e vermiculita estéreis na proporção de 2:1, e deixado em casa de vegetação para germinação.
As plântulas foram coletadas 30 dias após a germinação, e o número de células de G. diazotrophicus foi quantificado pela técnica de número mais provável (Döbereiner et al., 1995), em meio de cultura semi-sólido LGI-P caldo (Reis et al., 1994). Para o isolamento de G. diazotrophicus, foram utilizados os frascos que apresentaram crescimento bacteriano nas diluições maiores. Amostras das soluções contidas nos frascos foram semeadas em placas com meio de cultura LGI-P (Döbereiner et al., 1995) e incubadas por dez dias, a $30^{\circ} \mathrm{C}$, no escuro; em seguida foram purificadas e estocadas.

Foram obtidos 52 isolados de G. diazotrophicus, que foram testados com sete representantes da espécie: PAL3 $^{\mathrm{T}}, \mathrm{PAL}^{\mathrm{T}}, \mathrm{PRJ}^{\mathrm{T}}$, PSP17, PRJ14, CFNE501 e CFNE550, em meio de cultura líquido LGI (Döbereiner et al., 1995), suplementado com $10 \mathrm{mM}$ de $\mathrm{NH}_{4} \mathrm{SO}_{4}$, a pH 6.

Inicialmente, os isolados cresceram em meio de cultura líquido SYP (Caballero-Mellado \& MartinezRomero, 1994), por 24 horas, e $20 \mu \mathrm{L}$ deste meio foi introduzido em três frascos com $5 \mathrm{~mL}$ de meio de cultura líquido LGI sem sacarose, acrescido das seguintes fontes de carbono: glicose, xilitol, rafinose $\mathrm{D}(+)$, lactose, ribose $\mathrm{D}(-)$, galactose $\mathrm{D}(+)$, manitol, meso-eritritol, manose L(-), dulcitol, raminose $\mathrm{L}(-)$, trealose $\mathrm{D}(+)$, tartarato de Na e K, adonitol, mio-inositol, sorbitol D(-), arabinose $\mathrm{D}(-)$; e os ácidos: itacônico, vanílico, propiônico, coumárico, oxálico, benzóico, aconítico, tartárico, isovalérico, isobutírico e siríngico, na concentração de $10 \mathrm{mM}$ para açúcares, e $2 \mathrm{mM}$ para ácidos e compostos fenólicos.

Os isolados foram mantidos sob agitação constante a $75 \mathrm{rpm}$, por 72 horas, a $30^{\circ} \mathrm{C}$, e foram medidos a multiplicação celular, por meio da densidade ótica (492 nm), e o $\mathrm{pH}$ ao final do crescimento. Os valores de densidade ótica foram associados pela análise de agrupamento, utilizando o programa NTSYS, coeficiente Bray Curts, e pelo método de agrupamento pela associação média (UPGMA - Unweighted Pair-Group Method using Arithmetic Average). Os grupos formados com 30\% de distância foram utilizados para o cálculo do índice de diversidade de Shannon, e os valores para este índice foram submetidos à análise estatística, pelo teste $\mathrm{t}$ de Student, para avaliar se estes eram estatisticamente diferentes entre si (Magurran, 1987).

Em meio de cultura semi-sólido LGI, foi testada a capacidade de utilização de 40 fontes de carbono, em 22 isolados novos e mais sete estirpes da espécie. 
As formas testadas foram: glicose, xilitol, rafinose $\mathrm{D}(+)$, lactose, ribose $\mathrm{D}(-)$, manitol, meso-eritritol, manose L(-) e $\mathrm{D}(+)$, dulcitol, raminose, trealose $\mathrm{D}(+)$, tartarato de Na e $\mathrm{K}$, sorbose $\mathrm{D}(+)$ e $\mathrm{L}(-)$, talose $\mathrm{L}(-)$, galactose $\mathrm{L}(-), \mathrm{D}(+)$ e $\mathrm{D}(-)$, xilose $\mathrm{DL}$ e $\mathrm{L}(-)$, celobiose $\mathrm{D}(+)$, maltose $\mathrm{D}(+)$ e D(-), arabitol L(-) e D(+), catecol, palatinose, melibiose; e osácidos: itacônico, vanílico, propiônico, coumárico, oxálico, benzóico, aconítico, tartárico DL e L(+), siríngico, e caféico, na concentração de $10 \mathrm{mM}$ para açúcares, e $2 \mathrm{mM}$ para ácidos e compostos fenólicos. Os isolados cresceram como descrito na etapa anterior, e $20 \mu \mathrm{L}$ foram usados como inóculos em 3 frascos com $5 \mathrm{~mL}$ de meio de cultura LGI semi-sólido.

A capacidade de uso das fontes de carbono foi avaliada pela formação de película característica aos 10 dias de incubação, a $30^{\circ} \mathrm{C}$. Os grupos formados com $40 \%$ de similaridade foram utilizados para o cálculo do índice de diversidade de Shannon, e os valores para este índice foram submetidos à análise estatística pelo teste t de Student (Magurran, 1987).

A capacidade de formação de pigmento róseo em presença de luz foi avaliada mediante o crescimento dos isolados em placas de Petri, com meio de cultura sólido MS (Murashige \& Skoog, 1962), pH 6, suplementado com $10 \mathrm{~g} \mathrm{~L}^{-1}$ de frutose. A capacidade de formação de pigmento foi avaliada depois de 7 dias de incubação, em câmara a $30^{\circ} \mathrm{C}$ e com luz constante.

\section{Resultados e Discussão}

A população de Gluconacetobacter diazotrophicus, presente nas plântulas de cana-de-açúcar, variou de $11 \times 10^{4}$ a $18 \times 10^{5}$ células por grama de matéria fresca de tecido vegetal e foi maior nas amostras de raízes (Tabela 1). Resultados semelhantes foram encontrados por Perin (2003), com uma nova estratégia para isolar G. diazotrophicus, mediante o uso do meio de cultivo LGI-P, com caldo de cana (Reis et al., 1994). Esse meio de cultivo, aplicado em amostras de tecido, oriundas de toletes pré-germinados de cana-de-açúcar, facilita o isolamento dessa bactéria, em comparação com a utilização de pedaços de colmos (não germinados). Os toletes germinados são o material ideal para o isolamento de G. diazotrophicus, em razão da presença de alto número de bactérias dessa espécie.

A população foi maior nas variedades brasileiras de cana-de-açúcar, e variou de $3 \times 10^{5}$ a $18 \times 10^{5}$ células por grama de matéria fresca de tecido vegetal. Vale ressaltar que a cultura de cana-de-açúcar no Brasil recebe menores doses de fertilizantes nitrogenados, comparado a outros países (Baldani et al., 2002). Neste banco de germoplasma não foi aplicado fertilizante nitrogenado, o que estimulou a população de bactérias diazotróficas,

Tabela 1. Dados ecológicos e densidade populacional, em meio de cultura LGI-P, dos isolados de G. diazotrophicus obtidos de plantas de cana-de-açúcar cultivadas no Banco de Germoplasma da Pesagro, RJ.

\begin{tabular}{|c|c|c|c|c|}
\hline País de origem & Variedade & Isolado & Parte da planta & Populaçãoo ${ }^{(1)}$ \\
\hline \multirow[t]{12}{*}{ Brasil } & RB 739359 & $3 F-2$ & Parte aérea & 1,5 \\
\hline & RB 739359 & $3 R-2$ & Raízes & 1,5 \\
\hline & SP71-1406 & $4 \mathrm{~F}-4$ & Parte aérea & 20 \\
\hline & SP71-1406 & $4 \mathrm{R}-2$ & Raízes & 0,95 \\
\hline & SP70-1143 & $5 \mathrm{~F}-2$ & Parte aérea & 14 \\
\hline & SP70-1143 & $5 R-2$ & Raízes & 180 \\
\hline & RB 739735 & $18 \mathrm{R}-2$ & Raízes & 14 \\
\hline & CB 7437 & $20 \mathrm{~F}-2$ & Parte aérea & 1,5 \\
\hline & CB 737 & $21 \mathrm{~F}-2$ & Parte aérea & 2 \\
\hline & PB 4672 & 26R-2 & Raízes & 0,3 \\
\hline & PB 4612 & $30 \mathrm{R}-4$ & Raízes & 1,1 \\
\hline & PB 46126 & $34 \mathrm{R}-2$ & Raízes & 1,5 \\
\hline \multirow[t]{9}{*}{ Estados Unidos } & CP 5376 & $8 F-2$ & Parte aérea & 2 \\
\hline & CP 5376 & $8 \mathrm{R}-2$ & Raízes & 14 \\
\hline & CP 5329 & $9 \mathrm{~F}-2$ & Parte aérea & 0,95 \\
\hline & CP 5480 & $17 \mathrm{R}-4$ & Raízes & 0,3 \\
\hline & CP 595 & $19 \mathrm{~F}-4$ & Parte aérea & 0,3 \\
\hline & CP 595 & $19 \mathrm{R}-2$ & Raízes & 1,5 \\
\hline & CP 601 & 23R-2 & Raízes & 0,3 \\
\hline & CP 5268 & $24 \mathrm{~F}-2$ & Parte aérea & 0,15 \\
\hline & CP 5268 & $24 \mathrm{R}-6$ & Raízes & 0,2 \\
\hline \multirow[t]{6}{*}{ Índia } & CO 622 & $10 \mathrm{~F}-2$ & Parte aérea & 1,5 \\
\hline & CO 1007 & $11 \mathrm{~F}-2$ & Parte aérea & 2 \\
\hline & CO 1007 & $11 \mathrm{R}-2$ & Raízes & 14 \\
\hline & CO 740 & $12 \mathrm{~F}-2$ & Parte aérea & 0,2 \\
\hline & CO 740 & $12 \mathrm{R}-2$ & Raízes & 2 \\
\hline & $\mathrm{CO} 453$ & $15 \mathrm{~F}-2$ & Parte aérea & 0,2 \\
\hline \multirow[t]{4}{*}{ Barbados } & B 4098 & $28 \mathrm{~F}-2$ & Parte aérea & 0,3 \\
\hline & B 37161 & $32 \mathrm{~F}-6$ & Parte aérea & 0,3 \\
\hline & B 37161 & $32 \mathrm{R}-6$ & Raízes & 0,2 \\
\hline & B37172 & $33 \mathrm{R}-2$ & Raízes & 0,3 \\
\hline \multirow[t]{5}{*}{ Java } & POJ 2061 & $27 R-4$ & Raízes & 140 \\
\hline & POJ 2878 & $29 \mathrm{R}-2$ & Raízes & 0,3 \\
\hline & POJ 2878 & $29 \mathrm{R}-4$ & Raízes & 0,3 \\
\hline & POJ2714 & $36 \mathrm{~F}-4$ & Parte aérea & 0,11 \\
\hline & POJ2714 & $36 \mathrm{R}-2$ & Raízes & 0,3 \\
\hline \multirow[t]{4}{*}{ Havaí } & H 731933 & $40 \mathrm{~F}-4$ & Parte aérea & 0,3 \\
\hline & H 731933 & $40 \mathrm{R}-4$ & Raízes & 0,07 \\
\hline & H 493533 & $42 \mathrm{~F}-2$ & Parte aérea & 0,11 \\
\hline & H 493533 & $42 \mathrm{R}-2$ & Raízes & 0,11 \\
\hline \multirow[t]{3}{*}{ Porto Rico } & PR 1124 & $41 \mathrm{R}-2$ & Raízes & 140 \\
\hline & PR 097 & $37 \mathrm{~F}-2$ & Parte aérea & 0,2 \\
\hline & PR 097 & $37 \mathrm{R}-2$ & Raízes & 0,3 \\
\hline México & Mex 5217 & $31 \mathrm{R}-2$ & Raízes & 0,2 \\
\hline \multirow[t]{2}{*}{ Argentina } & $\mathrm{Na} 5679$ & $35 \mathrm{~F}-2$ & Parte aérea & 0,2 \\
\hline & $\mathrm{Na} 5679$ & $35 \mathrm{R}-2$ & Raízes & 0,3 \\
\hline \multirow[t]{2}{*}{ Cuba } & Pepe Cuca & $38 \mathrm{~F}-2$ & Parte aérea & 0,3 \\
\hline & Pepe Cuca & $38 \mathrm{R}-2$ & Raízes & 0,3 \\
\hline \multirow[t]{2}{*}{ Peru } & A. C. Grande ${ }^{(2)}$ & $39 \mathrm{~F}-2$ & Parte aérea & 0,15 \\
\hline & A. C. Grande ${ }^{(2)}$ & $39 \mathrm{R}-6$ & Raízes & 0,3 \\
\hline \multirow[t]{2}{*}{ Austrália } & Ragnar & $16 \mathrm{~F}-4$ & Parte aérea & 0,3 \\
\hline & Ragnar & $16 \mathrm{R}-2$ & Raízes & 0,2 \\
\hline
\end{tabular}

(1)Número mais provável $\times 10^{4}$ bactérias por grama de tecido vegetal. ${ }^{(2)}$ Azul Casa Grande. 
especialmente nos genótipos brasileiros. G diazotrophicus é uma bactéria endofítica e disseminada, principalmente, via propagação vegetativa pelos toletes, portanto pode expressar o histórico de cultivo do país de origem da planta hospedeira.

A população e o isolamento de G. diazotrophicus foi menor em países como Filipinas (Gonzales \& Barraquio, 2000) e México (Jimenez-Salgado et al., 1997), fato relacionado à presença de altas doses de fertilizantes nitrogenados. Também Fuentes-Ramirez et al. (1993) obtiveram baixa freqüência de isolamento (1,1 a 2,5\% das amostras avaliadas) em áreas com altas doses de fertilizantes nitrogenados (275-300 kg ha-1). Em áreas com menores doses, essa freqüência passou para valores de 10 a 67\%, o que sugere que a associação entre bactérias diazotróficas e a cana-de-açúcar pode ser severamente limitada com a aplicação de altas doses de fertilizantes nitrogenados, provavelmente pela redução da síntese de sacarose, que é afetada pelas altas doses de nitrogênio (Pelaez Abellan et al., 1994).

Das 28 fontes de carbono testadas em meio de cultura líquido, apenas três foram usadas por um número expressivo de isolados. A glicose foi utilizada por todos, seguida de sorbitol e maltose, utilizados pela maioria. Dos ácidos orgânicos testados, apenas os ácidos vanílico e siríngico foram utilizados por seis isolados e por um isolado, respectivamente. Nenhum isolado cresceu na presença de rafinose, lactose, ribose, galactose, raminose, manitol, meso-eritritol, dulcitol, e dos ácidos itacônico, propiônico, coumárico, oxalacético, benzóico, isovalérico, isobutírico e tartárico. Apenas alguns isolados cresceram usando xilitol (7), adonitol (4), mio-inositol (3), arabinose (11), tartarato de sódio e potássio (9), trealose (7), ácido vanílico (6), e apenas o isolado 3F-2 utilizou o ácido siríngico.

O dendrograma construído a partir das 15 fontes de carbono, utilizadas para crescimento em meio de cultura líquido, e formado pelo agrupamento dos isolados que apresentaram variação no padrão de utilização, é apresentado na Figura 1. Podem ser distinguidos dois grandes grupos com $48 \%$ de diferença. No grupo 1 está a maioria dos isolados, e o grupo 2 engloba apenas nove isolados, todos distribuídos aleatoriamente, em relação à parte da planta, variedade de cana-de-açúcar da qual foi isolado, e o seu país de origem.

Em nível menor de discriminação, formaram-se seis grupos com $40 \%$ de diferença entre si, também distribuídos aleatoriamente, em relação aos seus dados ecológicos.
Observa-se que quando analisados separadamente, com $30 \%$ de diferença, os isolados de raízes formaram oito grupos, e que aqueles obtidos da parte aérea formaram seis grupos. A diversidade calculada pelo índice de Shannon foi de 0,66, para os isolados da parte aérea, e 0,8 para os isolados do sistema radicular, os quais não diferiram estatisticamente entre si, pelo teste t de Student.

O valor de pH do meio de cultura LGI, suplementado com as 15 fontes de carbono que apresentaram variação no padrão de utilização pelos isolados, foi de 4,5, em média; na presença de glicose - a única fonte de carbono usada por todos os isolados - foi de 2,8 , tendo variado de 2,44 a 3,46.

Das 40 fontes de carbono testadas em meio de cultura LGI semi-sólido, 26 foram utilizadas. A glicose foi utilizada por todos os isolados, como ocorreu no meio de cultura líquido. Das três formas de galactose testadas, apenas a galactose $\mathrm{D}(+)$ foi usada pela maioria dos isolados. A rafinose $\mathrm{D}(+)$, única forma testada, comportou-se semelhantemente, tendo apresentado crescimento por um número elevado de isolados. As demais variaram de 11 a um isolado (Figura 2). As fontes de carbono: sorbose $\mathrm{D}(+)$ e $\mathrm{L}(-)$, talose $\mathrm{L}(-)$, galactose $\mathrm{L}(-)$ e $\mathrm{D}(+)$, arabitol L(-), lactose, catecol, dulcitol, palatinose, xilose $\mathrm{DL}$, ribose $\mathrm{D}(-)$, arabitol $\mathrm{D}(+)$, e os ácidos caféico, siríngico, coumárico, tartárico, vanílico e itacônico não foram usadas pelos isolados testados. Em geral, a condição de uso do meio semi-sólido, que propicia o crescimento sob condições de fixação biológica de nitrogênio, favoreceu o crescimento em um maior número de fontes de carbono. Ácido propiônico, ribose e raminose só foram utilizados em meio de cultura semi-sólido. Comparando-se o uso de fontes de carbono em cultivos em meio semi-sólido, entre os isolados de raiz e parte aérea, observa-se que 16 isolados de raízes usaram 26 fontes de carbono, e 13 isolados de parte aérea utilizaram apenas nove fontes.

A diversidade calculada pelo índice de Shannon foi de 0,63 , para os isolados do sistema radicular, e 0,12 para os isolados de parte aérea, os quais diferiram estatisticamente entre si, pelo teste $t$ de Student. O uso de maior número de fontes de carbono, por isolados obtidos do sistema radicular, provavelmente, ocorreu em virtude da menor concentração de glicose nas raízes, fonte de carbono preferida por esta população, levando ao uso de fontes alternativas.

Não foi observado nenhum efeito seletivo da variedade de cana-de-açúcar e país de origem, como já ob- 
servado por Perin (2003), que avaliou o uso de fontes de carbono por isolados de G. diazotrophicus obtidos de cana-de-açúcar, que também apresentaram crescimento em poucas fontes de carbono. Porém, é espera-

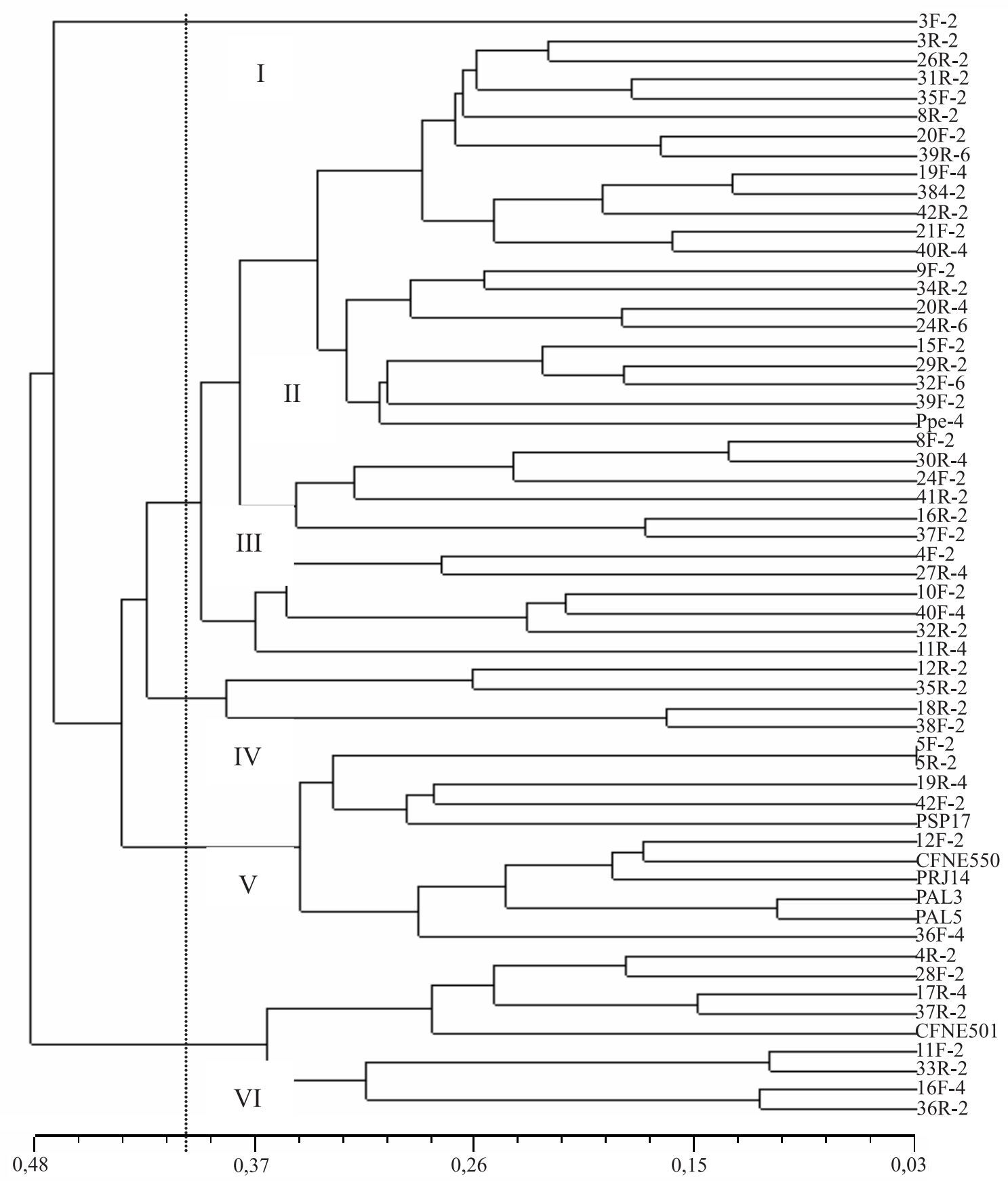

Figura 1. Dendrograma de distância, gerado pelo uso de fontes de carbono, em meio de cultura líquido, pelos isolados de G. diazotrophicus obtidos de cultivares de cana-de-açúcar mantidas no Banco de Germoplasma de Campos dos Goytacazes, RJ, e estirpes padrões da mesma espécie, a partir do índice Bray Curts e método UPGMA. I, II, III, IV, V e VI: grupos formados com 40\% de diferença entre os isolados. Isolados identificados com número seguido da letra F são provenientes da parte aérea, e isolados identificados com número seguido da letra R são provenientes do sistema radicular. 
do o agrupamento dos isolados, em relação ao local de cultivo (Perin et al., 2004), que indica que o tipo de solo e manejo podem interferir na população de G. diazotrophicus, como também verificado na população de Azospirillum amazonense isolada de arroz (Azevedo, 1998) e Brachiaria (Reis Junior et al., 2004).

Para Kirchhof et al. (1997), a baixa diversidade de diazotróficas endofíticas pode estar relacionada ao seu habitat, ou à adaptação desta população às condições específicas do interior das plantas e, por isso, a estrutura genética da população dessas bactérias seria limitada e altamente conservada. Esta baixa variabilidade,

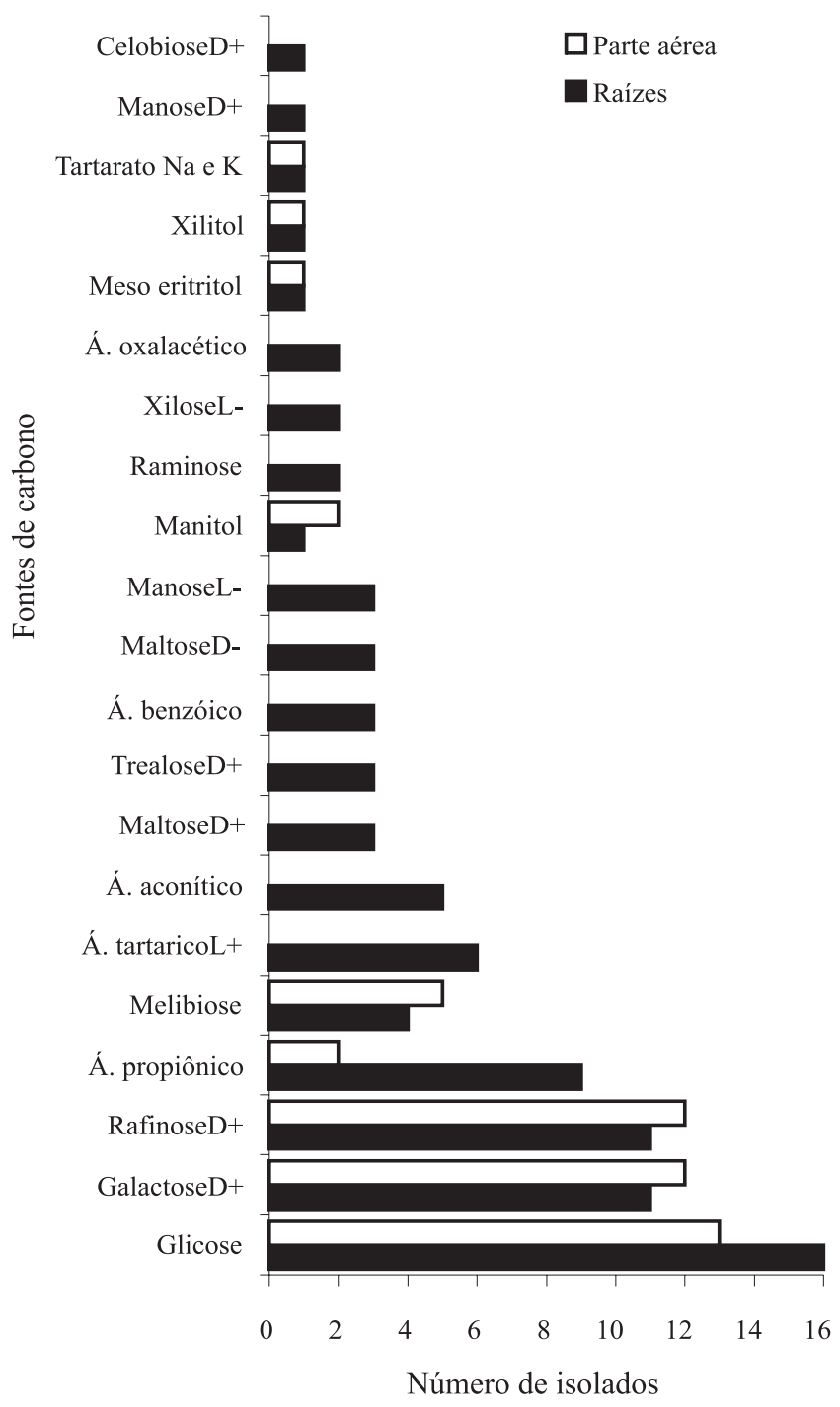

Figura 2. Utilização de fontes de carbono, em meio de cultura LGI semi-sólido, por estirpes e isolados de G. diazotrophicus, obtidas do sistema radicular e parte aérea de cultivares de cana-de-açúcar. verificada nos isolados de G. diazotrophicus que colonizam cultivares de cana-de-açúcar de diferentes origens geográficas, indica baixa especificidade planta/bactéria, e possibilita que estirpes selecionadas em trabalhos de inoculação, por apresentarem melhores respostas no desenvolvimento das plantas, possam ser utilizadas em qualquer variedade de cana-de-açúcar, não exigindo que a cada trabalho de melhoramento seja feita, juntamente, seleção de estirpes de G. diazotrophicus.

Dos isolados testados, foi observada formação de pigmento róseo apenas na estirpe padrão da espécie Ppe-4, considerada controle positivo, e nos isolados 36F-4, 37F-2, 38R-2 e 40F-2. A produção de pigmentos em presença de luz é uma forma de proteção dos organismos, ou pode ser indício de organismos fototróficos. Em sua maioria, são metabólitos secundários, e alguns têm propriedades antibióticas. Este pigmento não foi identificado até o momento, sendo necessários mais estudos para sua identificação, que pode resultar em seu uso biotecnológico.

\section{Conclusões}

1. O número populacional de G. diazotrophicus é maior no sistema radicular, em relação à parte aérea, e maior nas variedades brasileiras de cana-de-açúcar.

2. Os isolados de G. diazotrophicus usam poucas fontes de carbono, e a glicose é utilizada por todos.

3. Poucos isolados de G. diazotrophicus formam pigmento róseo em presença de luz.

\section{Agradecimentos}

Ao CNPq, à Capes e à Faperj, pela concessão de bolsas; ao Programa de Apoio a Núcleos de Excelência (Pronex II), pelo apoio financeiro.

\section{Referências}

AZEVEDO, M.S. Influência do solo e da planta hospedeira sobre a diversidade gênica de isolados de Azospirillum amazonense associados às raízes de arroz, milho e sorgo. 1998. 110p. Dissertação (Mestrado) - Universidade Federal Rural do Rio de Janeiro, Seropédica, RJ.

BALDANI, J.I.; REIS, V.M.; BALDANI, V.L.D.; DÖBEREINER, J. A brief story of nitrogen fixation in sugarcane - reasons for success in Brazil. Functional Plant Biology, v.29, p.417-423, 2002.

BASTIAN, F.; RAPPARINI, F.; BARALDI, R.; PICCOLI, P.; BOTTINI, R. Inoculation with Acetobacter diazotrophicus increases glucose and fructose content in shoots of Sorghum bicolor (L.) Moench. Symbiosis, v.27, p.147-156, 1999.

CABALLERO-MELLADO, J.; MARTINEZ-ROMERO, E. Limited genetic diversity in the endophytic sugarcane bacterium Acetobacter diazotrophicus. Applied and Environmental Microbiology, v.60, p.1532-1537, 1994. 
CANUTO, E.L.; SALLES, J.F.; OLIVEIRA, A.L.M.; PERIN, L.; REIS, V.M.; BALDANI, J.I. Resposta de plantas micropropagadas de cana-de-açúcar à inoculação de bactérias diazotróficas endofíticas. Agronomia, v.37, p.67-72, 2003.

CAVALCANTE, V.A.; DÖBEREINER, J. A new acid-tolerant nitrogen-fixing bacterium associated with sugarcane. Plant and Soil, v.108, p.23-31, 1988

DÖBEREINER, J.; BALDANI, V.L.D.; BALDANI, J.I. Como isolar e identificar bactérias diazotróficas de plantas não leguminosas. Brasília, DF: Embrapa-SPI; Itaguaí: Embrapa-CNPAB, 1995. 60p.

EMBRAPA. Centro Nacional de Pesquisa de Solos (Rio de Janeiro, RJ). Sistema brasileiro de classificação de solos. Brasília: Embrapa-SPI, 1999. 412p.

FUENTES-RAMIREZ，L.E.; JIMENEZ-SALGADO，T.; ABARCA-OCAMPO, I.R.; CABALLERO-MELLADO, J. Acetobacter diazotrophicus, an indoleacetic acid producing bacterium isolated from sugarcane cultivars of México. Plant and Soil, v.154, p.145-150, 1993.

GONZALEZ, M.S.; BARRAQUIO, W.L. Isolation and characterization of Acetobacter diazotrophicus (Gillis) in Saccharum officinarum L., Saccharum spontaneum L., and Erianthus sp. Philippine Agricultural Scientist, v.83, p.173-181, 2000.

JIMENEZ-SALGADO, T.; FUENTES-RAMIRES, L.E.; TAPIAHERNANDEZ, A.; MASCARUA-ESPARZA, M.A.; MARTINEZ-ROMERO, E.; CABALLERO-MELLADO, J. Coffea arabica L., a new host plant for Acetobacter diazotrophicus, and isolation of other nitrogen-fixing acetobacteria. Applied and Environmental Microbiology, v.63, p.3676-3683, 1997.

KIRCHHOF, G.; REIS, V.M.; BALDANI, J.I.; ECKERT, B.; DÖBEREINER, J.; HARTMANN, A. Occurrence, physiological and molecular analysis of endophytic diazotrophic bacteria in gramineous energy plants. Plant and Soil, v.194, p.45-55, 1997.

LIMA, E.; BODDEY, R.M.; DÖBEREINER, J. Quantification of biological nitrogen-fixation associated with sugar cane using a ${ }^{15} \mathrm{~N}$ aided nitrogen balance. Soil Biology and Biochemistry, v.19, p.165170, 1987.

MAGURRAN, A.E. Ecological diversity and its measurement. Princeton, NJ: Princeton University Press, 1987. 179p.

MURASHIGE, T.; SKOOG, F. A revised medium for rapid growth and bio assays with tobacco tissue cultures. Physiologia Plantarum, v.15, p.473-497, 1962.
MUTHUKUMARASAMY, R.; REVATHI, G.; LAKSHMINARASIMHAN, C. Diazotrophic associations in sugar cane cultivation in South India. Tropical Agriculture, v.76, p.171178, 1999.

ORLANDO-FILHO, J.; HAAG, H.P.; ZAMBELLO JUNIOR, E. Crescimento e absorção de macronutrientes pela cana-deaçúcar, variedade CB 41-76 em função da idade em solos do Estado de São Paulo. Piracicaba: Planalsucar, 1980. 128p. (Planalsucar. Boletim técnico, 2).

PELAEZ ABELLAN, I.; ARMAS URQUIZA, R. de; VALADIER, M.-H.; CHAMPIGNY, M.-L. Short-term effect of nitrate on carbon metabolism of two sugar cane cultivars differing in their biomass production. Phytochemistry, v.36, p.819-823, 1994.

PERIN, L. Ecologia e diversidade de Gluconacetobacter diazotrophicus associados à cultura da cana-de-açúcar (Saccharum spp.). 2003. 63p. Dissertação (Mestrado) Universidade Federal Rural do Rio de Janeiro, Seropédica, RJ.

PERIN, L.; BALDANI, J.I.; REIS, V.M. Diversidade de Gluconacetobacter diazotrophicus isolada de plantas de cana-deaçúcar cultivadas no Brasil. Pesquisa Agropecuária Brasileira, v.39, p.763-770, 2004.

REIS, V.M.; DÖBEREINER, J. Effect of high sugar concentration on nitrogenase activity of Acetobacter diazotrophicus. Archives of Microbiology, v.171, p.13-18, 1998.

REIS, V.M.; OLIVARES, F.L.; DÖBEREINER, J. Improved methodology for isolation of Acetobacter diazotrophicus and confirmation of its endophytic habitat. World Journal of Microbiology and Biotechnology, v.10, p.401-405, 1994.

REIS JUNIOR, F.B. dos; SILVA, L.G. da; REIS, V.M.; DÖBEREINER, J. Ocorrência de bactérias diazotróficas em diferentes genótipos de cana-de-açúcar. Pesquisa Agropecuária Brasileira, v.35, p.985-994, 2000.

REIS JUNIOR, F.B. dos; SILVA, M.F. da; TEIXEIRA, K.R.S.; URQUIAGA, S.; REIS, V.M. Intra-specific diversity study of the nitrogen fixing bacterium Azospirillum amazonense isolated from different Brachiaria species. Symbiosis, v.36, p.41-56, 2004.

URQUIAGA, S.; CRUZ, K.H.S.; BODDEY, R.M. Contribution of nitrogen fixation to sugar cane: nitrogen-15 and nitrogen-balance estimates. Soil Science Society of America Journal, v.56, p.105114, 1992.

Recebido em 30 de março de 2005 e aprovado em 20 de outubro de 2005 